\title{
Displacement-based internal design of geosynthetic-reinforced earth structures subjected to seismic loading conditions
}

\author{
F. VAHEDIFARD*, D. LESHCHINSKY $\dagger$ and C. L. MEEHAN†
}

\begin{abstract}
A majority of the existing analytical approaches for displacement-based seismic design of geosynthetic-reinforced earth structures (GRESs) have been developed by considering only a translational mode of failure (external sliding stability), and consequently do not provide a means for assessing the seismic displacement of GRESs due to rotational movements (internal stability). Internal rotational failure can degenerate to a translational one should it be more critical; however, the reverse is not true, which makes rotational failure a more generic mechanism. To address this issue, this paper presents a new analytical-numerical framework for the displacement-based design of GRESs, which assesses the potential for earthquake-induced displacements via an internal stability (rotational) failure mechanism. For design purposes, in order to determine the superimposed force in the reinforcement due to seismicity and its associated displacement, the proposed approach examines two limiting conditions: (a) the upper-bound force that can be mobilised in the reinforcement, as determined by pseudo-static limit equilibrium; and (b) the force that can be induced in the reinforcement by a given earthquake acceleration applied over a finite time increment. Either condition satisfies equilibrium. The prevailing seismically induced force and displacement in the reinforcement for each time increment are determined by selecting the smaller value that results from these two conditions. As an auxiliary tool, a set of pullout simulations was performed using finite-element analysis in order to relate the force and displacement in the geosynthetic reinforcement for various geosynthetic stiffnesses. To illustrate the application of the proposed method, a design example using a Kobe earthquake record is presented. For this example, the superimposed force in the reinforcement due to seismicity, the seismic displacement, and the seismic rotation are calculated. The required unfactored geosynthetic strength is then determined using a uniform distribution function.
\end{abstract}

KEYWORDS: design; earthquakes; geosynthetics; limit equilibrium methods; reinforced soils; seismicity

\section{INTRODUCTION}

The post-earthquake serviceability of geosynthetic-reinforced earth structures (GRESs) is a major design concern that cannot be properly addressed using pseudo-static stability analysis methods alone. In addition, using pseudo-static stability analysis for designing GRESs can sometimes lead to irrationally large reinforcement lengths (Ling et al., 1997; Vahedifard et al., 2012). In the past few years, performancebased seismic design methods that calculate earthquakeinduced displacement have seen increased utilisation for GRESs (e.g. FHWA, 2009; NCMA, 2009). FHWA (2009) recommends a displacement-based design methodology for assessing the external seismic stability of mechanically stabilised earth (MSE) walls. Following this approach, the total (static and dynamic) thrust force is calculated using either the Mononobe-Okabe (M-O) formulation or a method called 'generalised limit equilibrium slope stability'.

In an ideal case, a fully coupled dynamic analysis using numerical modelling (i.e. finite-element (FE) or finitedifference (FD) methods) can provide the most accurate prediction of stress-deformation behaviour of GRESs under seismic loading, by considering all potential deformation mechanisms. However, this type of seismic analysis is

Manuscript received 25 October 2011; revised manuscript accepted 11 September 2012. Published online ahead of print 14 November 2012. Discussion on this paper closes on 1 October 2013, for further details see p. ii.

* Department of Civil and Environmental Engineering, Mississippi State University, MS, USA.

$\dagger$ Department of Civil and Environmental Engineering, University of Delaware, Newark, DE, USA. computationally expensive, and requires several difficult-todetermine input parameters along with a relatively high level of engineering expertise to execute effectively. As a compromise between the simple pseudo-static method and the more complex numerical techniques that are available, analytical displacement-based methods offer a number of advantages: they are already commonly used in practice for unreinforced slope displacement predictions, so practitioners are familiar with their use; they provide significantly more useful information than simple pseudo-static methods; they have a lower complexity and need fewer input parameters than traditional numerical modelling approaches; and they are believed by many to provide a reliable index of slope performance under seismic loading through their predictive calculation of permanent earthquake-induced displacements (e.g. Jibson, 2007).

Numerous analytical displacement-based methods currently exist for either predicting earthquake-induced displacements in GRESs or performing displacement-based design of GRESs (e.g. Cai \& Bathurst, 1996; Ling et al., 1997; Ausilio et al., 2000; Michalowski \& You, 2000; Huang et al., 2003; Paulsen \& Kramer, 2004; Nakajima et al., 2010). Most of these existing methods typically couple a pseudo-static limit equilibrium (LE) approach with an extension of Newmark's (1965) displacement-based analytical framework to determine earthquakeinduced displacements. Each of these analytical methods assumes a certain governing failure mechanism under seismic loading. The associated 'failure mass' of soil is determined from this initial failure mechanism assumption. For purposes of analysis or design, the failure mass is divided into a number of wedges, and the 'yield acceleration' (the pseudo-static coefficient that corresponds to a safety factor of one) is determined 
by solving the LE equations. A majority of the existing displacement-based pseudo-static LE methods (e.g. Cai \& Bathurst, 1996; Ling et al., 1997; Nakajima et al., 2010) were developed by considering only a translational mode of failure (i.e. external sliding stability) for calculating earthquakeinduced displacement, and consequently do not provide a means for assessing the seismic displacement of GRESs due to rotational movements (internal stability). This observation is of particular concern, as Leshchinsky et al. (2009) have demonstrated that internal stability may control the required tensile strength of the reinforcement for GRESs. Moreover, internal rotational failure can degenerate to a translational one should it be more critical (e.g. Leshchinsky \& Zhu, 2010); however, the reverse is not true, which makes rotational failure a more generic mechanism.

To address this issue, this paper presents a new analyticalnumerical framework for the displacement-based design of GRESs, which assesses the potential for earthquake-induced displacements via an internal stability (rotational) failure mechanism. For design purposes, in order to determine the superimposed force in the reinforcement due to seismicity and its associated displacement, the proposed approach examines two limiting conditions.

(a) The upper-bound force that can be mobilised in the reinforcement, as determined by pseudo-static LE. For a given earthquake acceleration, this would be the maximum force that can be induced in the reinforcement by the inertial response of the sliding body.

(b) The force that can be induced in the reinforcement by a given earthquake acceleration applied over a finite time increment. This second limiting condition examines the 'time limitation effect', which accounts for the transient characteristics of the applied ground motion.

The smaller of the forces yielded from these two conditions controls the seismically induced force and displacement in the reinforcement for each time increment. In order to relate the force and displacement in the geosynthetic reinforcement, a set of pullout simulations was performed using FE analysis for various geosynthetic stiffnesses. The summation of the incremental displacements and induced forces in the reinforcement over the entire time series analysis provides the necessary information to guide the design of a GRES.

\section{METHODOLOGY AND FORMULATION}

Leshchinsky et al. (2012) presented an analytical solution based on LE and using a log-spiral failure surface to extend the $\mathrm{M}-\mathrm{O}$ method for unreinforced slopes. Using a similar formulation, Vahedifard et al. (2012) proposed a pseudo-static LE approach for assessing the internal stability of GRESs that can be utilised for a given reinforcement strength to determine the yield acceleration required for calculating seismic displacements in Newmark-type methods. However, for design purposes, it is also desirable to have a displacement-based method to assess the required reinforcement strength under seismic conditions. The method proposed by Vahedifard et al. (2012) is utilised in this paper to determine the static resultant force in the reinforcement. For brevity, some fundamentals related to this paper are not reiterated here; interested readers are referred to Vahedifard et al. (2012).

The proposed model assumes a rotational (internal) mode of failure along a log-spiral failure surface (Fig. 1). The proposed model treats the reinforced soil mass inside the failure surface as a rigid body, and represents the reinforcement acting outside the failure surface as a spring. This approach assumes that the reinforcement layers hold the sliding mass coherent during shaking, and that consequently the internal deformations are not significant.

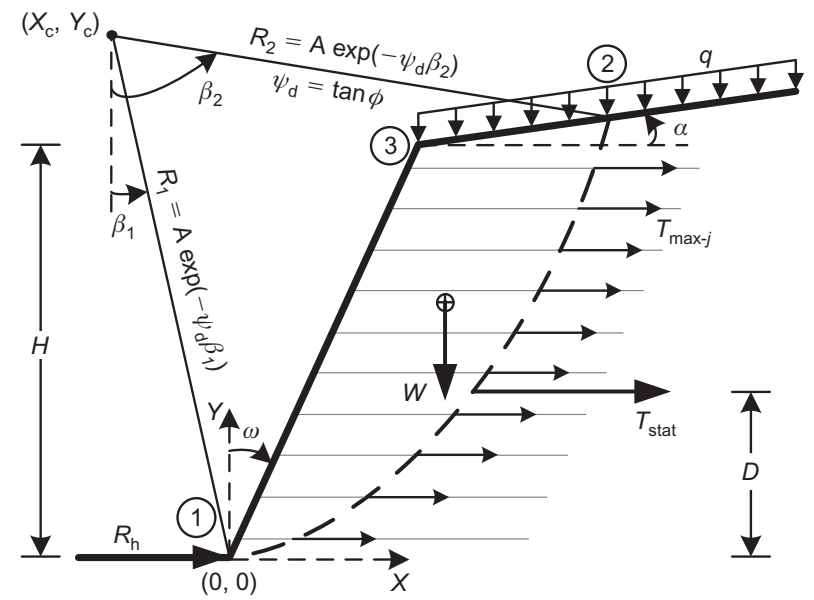

(a)

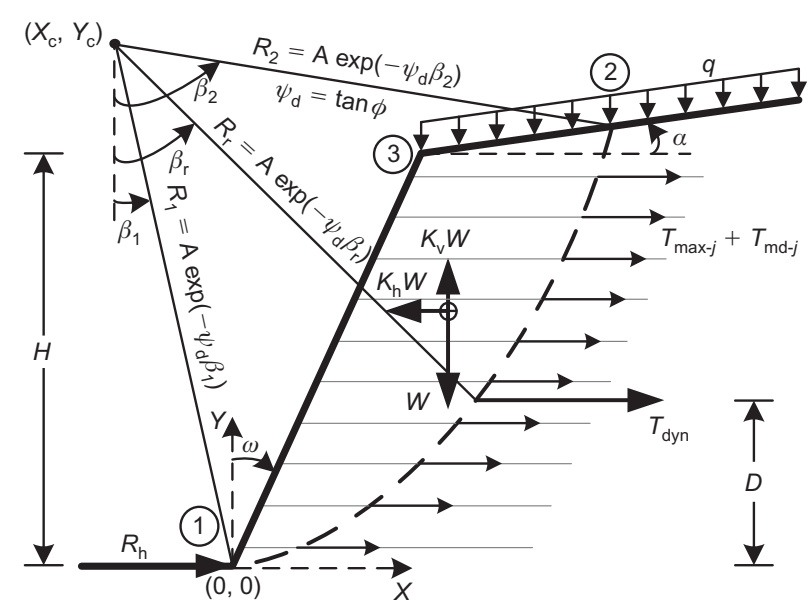

(b)

Fig. 1. Notation and convention: (a) static condition, state of LE; (b) dynamic condition, rotation initiated

Figure 2 shows the flow of calculations that are necessary to perform the displacement-based design process utilised in this paper. The associated assumptions that are made for each of the steps in the calculation are discussed in more detail in the following sections. As shown in Fig. 2, after calculating the mobilised resultant reinforcement force under static loading conditions $\left(T_{\text {stat }}\right)$, in a parallel attempt the seismic-induced displacement and force in the reinforcement are calculated using two approaches: a pseudo-static LE approach and an acceleration time-series integration approach. Since the induced force that is predicted by the time series approach cannot exceed the required force to satisfy equilibrium at each time increment, the LE equations provide an upper limit to the force and displacement that can be mobilised. As an auxiliary tool, a set of pullout simulations using FE analysis was performed to establish a rational relationship between reinforcement displacement and force during shaking. The scope of the proposed approach is limited to cases where pullout failure of the reinforcement does not control the internal design. This limitation is not a concern for most GRESs constructed using extensible reinforcement (e.g. geogrids or geotextiles), as this mode of failure is not an issue for nearly all typical design cases.

\section{Step 1: Static reinforcement force from limit equilibrium}

Leshchinsky et al. (2010) present stability charts for the static design of GRESs that fail internally via a rotational failure mechanism. These charts were developed for GRESs 


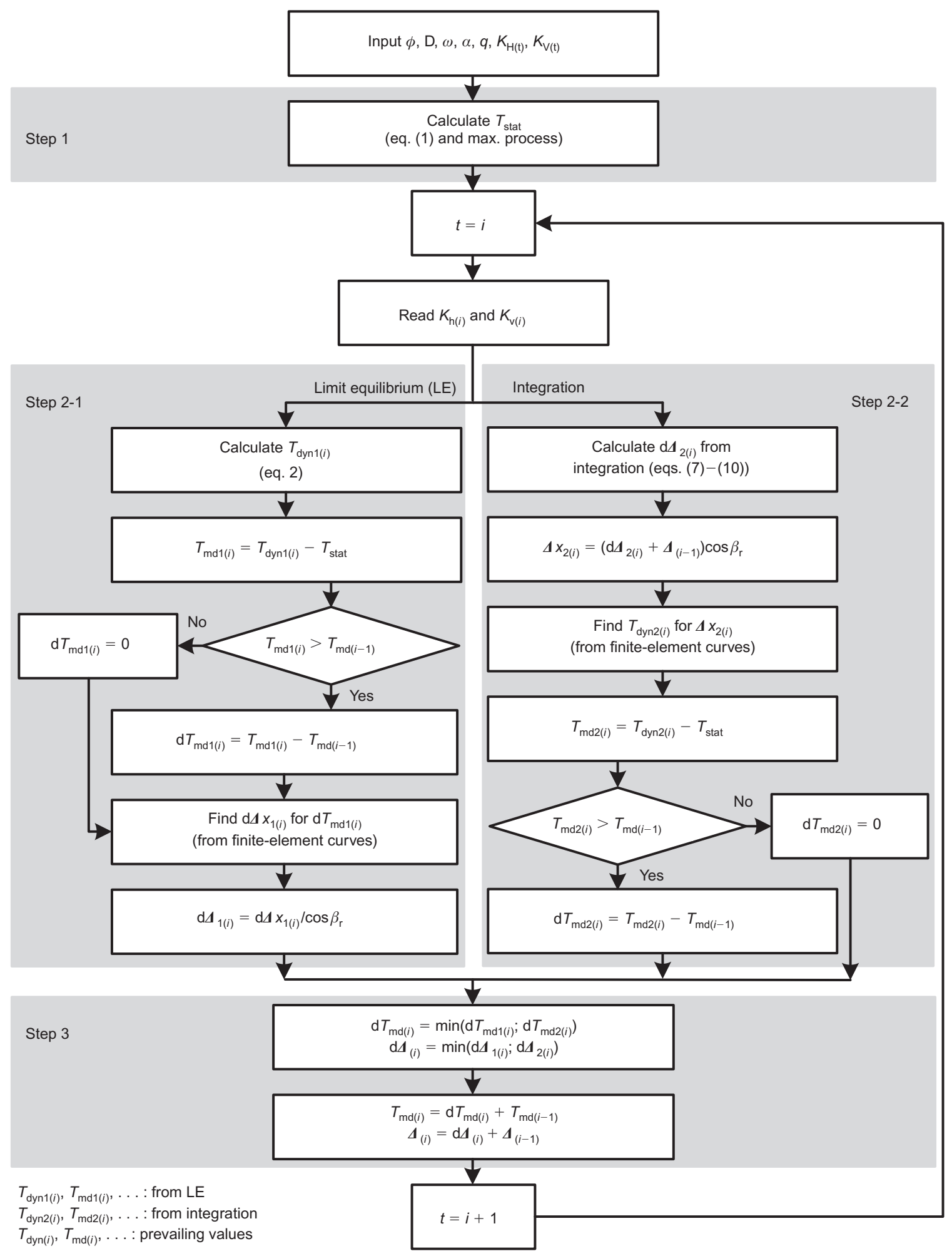

Fig. 2. Flow of calculations for proposed approach

constructed using cohesionless soils, and for horizontal backslope conditions. The general approach that was used to develop these stability charts can be extended as shown in Fig. 1(a) and equation (1) to allow for the static design of GRESs with an inclined backslope.

For a given log-spiral failure surface, static failure of the sliding mass is prevented by the reactive static force that is mobilised in the reinforcement. In order to determine the reinforcement force that is required to resist sliding, an LE analysis approach is applied. In this analysis, the trace of the log-spiral is defined by the radius vector $R=A \exp \left(-\psi_{\mathrm{d}} \beta\right)$, where $A$ is the log-spiral constant, $\psi_{\mathrm{d}}=\tan \left(\phi_{\text {design }}\right)$, and $\beta$ is the angle in polar coordinates. For a given log-spiral failure surface (Fig. 1(a)), the static reinforcement force that is needed for equilibrium $\left(T_{\text {stat }}\right)$ can be determined by applying moment equilibrium about the pole of the log-spiral (Leshchinsky et al., 2010; Vahedifard et al., 2012) 


$$
T_{\text {stat }}=\left\{\begin{array}{l}
\gamma \int_{\beta_{1}}^{\beta_{2}}\left(A \mathrm{e}^{-\psi_{\mathrm{d}} \beta} \cos \beta-A \mathrm{e}^{-\psi_{\mathrm{d}} \beta_{2}} \cos \beta_{2}\right)\left(A \mathrm{e}^{-\psi_{\mathrm{d}} \beta} \sin \beta\right)\left(A \mathrm{e}^{-\psi_{\mathrm{d}} \beta}\right)\left(\cos \beta-\psi_{\mathrm{d}} \sin \beta\right) \mathrm{d} \beta \\
-\frac{\gamma H^{2}}{2} \tan \omega\left(\frac{H}{3} \tan \omega+A \mathrm{e}^{-\psi_{\mathrm{d}} \beta_{1}} \sin \beta_{1}\right) \\
-\gamma H \tan \omega\left(A \mathrm{e}^{-\psi_{\mathrm{d}} \beta_{1}} \cos \beta_{1}-A \mathrm{e}^{-\psi_{\mathrm{d}} \beta_{2}} \cos \beta_{2}-H\right)\left(A \mathrm{e}^{-\psi_{\mathrm{d}} \beta_{1}} \sin \beta_{1}+\frac{H}{2} \tan \omega\right) \\
-\frac{\gamma}{2}\left(A \mathrm{e}^{-\psi_{\mathrm{d}} \beta_{2}} \sin \beta_{2}-A \mathrm{e}^{-\psi_{\mathrm{d}} \beta_{1}} \sin \beta_{1}-H \tan \omega\right)\left(A \mathrm{e}^{-\psi_{\mathrm{d}} \beta_{1}} \cos \beta_{1}-A \mathrm{e}^{-\psi_{\mathrm{d}} \beta_{2}} \cos \beta_{2}-H\right) \\
\times\left[A \mathrm{e}^{-\psi_{\mathrm{d}} \beta_{1}} \sin \beta_{1}+H \tan \omega+\frac{1}{3}\left(A \mathrm{e}^{-\psi_{\mathrm{d}} \beta_{2}} \sin \beta_{2}-A \mathrm{e}^{-\psi_{\mathrm{d}} \beta_{1}} \sin \beta_{1}-H \tan \omega\right)\right] \\
+\frac{q}{2}\left[\left(A \mathrm{e}^{-\psi_{\mathrm{d}} \beta_{2}} \sin \beta_{2}\right)^{2}-\left(A \mathrm{e}^{-\psi_{\mathrm{d}} \beta_{1}} \sin \beta_{1}+H \tan \omega\right)^{2}\right] \\
\div\left[\left(A \mathrm{e}^{-\psi_{\mathrm{d}} \beta_{1}} \cos \beta_{1}-D\right)+\frac{R_{\mathrm{h}}}{T_{\mathrm{stat}}}\left(A \mathrm{e}^{-\psi_{\mathrm{d}} \beta_{1}} \cos \beta_{1}\right)\right]
\end{array}\right\}
$$

where $\gamma$ is the unit weight of reinforced soil; $H$ is the height of the slope; $\alpha$ is the backslope angle; $\beta_{1}$ and $\beta_{2}$ are the angles of the points where the log-spiral enters and exits the slope (Fig. 1(a)); $\omega$ is the batter; $q$ is the surcharge; $D$ is the elevation of line of action of the resultant reinforcement force $\left(T_{\text {stat }}\right)$, and $R_{\mathrm{h}}$ is the horizontal resistance of the facing at the bottom of the slope. In this study, the impact of facing is not considered, and $R_{\mathrm{h}}$ is ignored; this is a legitimate assumption in certain structures, such as wrapped-face GRESs or smallblock facing walls. Because of publication space restrictions, the effects of toe resistance are ignored in the current study; toe resistance effects and their implications in the context of design of reinforced earth structures are addressed by Leshchinsky \& Vahedifard (2012). The elevation of $D$ is a function of the reinforcement spacing and the assumed distribution of the individual reinforcement forces; the effect of the assumed location of $D$ is examined in more detail by Vahedifard et al. (2012).

The maximum required static reinforcement force, $\max \left(T_{\text {stat }}\right)$, can be calculated by utilising a maximisation process in conjunction with equation (1); this process is explained in more detail by Leshchinsky et al. (2010). The objective of this process is to identify the test body that requires the maximum reactive force from the reinforcement that is needed to satisfy the LE state. This process yields values that are necessary to determine the "critical slip surface' $\left(X_{\mathrm{c}}, Y_{\mathrm{c}}\right.$ and $\left.A\right)$ that corresponds to the value of $\max \left(T_{\text {stat }}\right)$. Note that the equivalent reinforcement force under the static condition is assumed to act horizontally.
Step 2-1: Seismic reinforcement force and displacement from limit equilibrium

If unfactored soil strengths and geosynthetic reinforcement strengths equal to the reactive resistances are used in the equilibrium calculations, the GRES shown in Fig. 1(a) will be in a state of incipient static failure (i.e. it will be at its limit state, with its factor of safety $(\mathrm{FS})=1 \cdot 0)$. If any additional earthquake-induced forces are added to this system, the sliding mass will move. For GRES design purposes, additional reinforcement strength is needed to resist the earthquake-induced forces that are imposed to the system that is, the reinforcement needs to provide more strength to stabilise the GRES.

During earthquake shaking, the reinforced soil mass is subjected to additional seismic forces. As shown in Fig. 1(b), this shaking at each time increment can be represented by inertial forces that act at the centre of gravity of the sliding mass. In response to these inertial forces, the resultant force in the reinforcement $\left(T_{\mathrm{dyn} 1}\right)$ changes, and needs to be recalculated in response to the dynamic loading condition. For the purposes of the analyses herein, it is assumed that this resultant dynamic reinforcement force acts horizontally (Fig. 1(b)).

In a similar fashion as the calculations that were performed to determine $T_{\text {stat}}$, we can use the equation for moment equilibrium about the pole of the log-spiral to determine the associated value of the resultant dynamic force in the reinforcement from the LE approach $\left(T_{\mathrm{dyn} 1}\right)$ for each time increment in the analysis. 


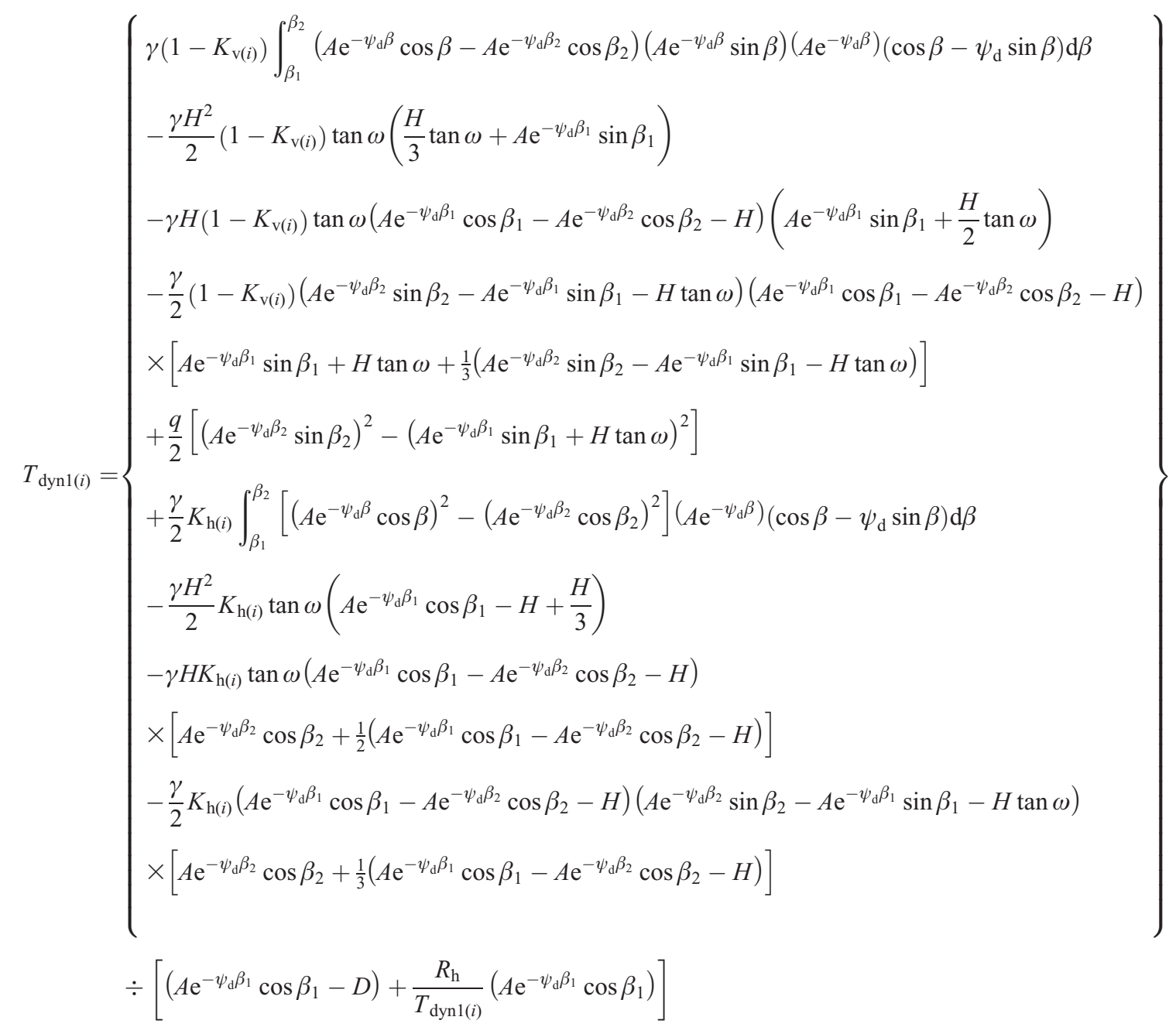

where $K_{\mathrm{h}(i)}$ and $K_{\mathrm{v}(i)}$ are the horizontal and vertical seismic coefficients at time increment $(i)$, and the other variables are as defined previously.

Entering the calculated $X_{\mathrm{c}}, Y_{\mathrm{c}}$ and A values from the static case (equation (1)) into equation (2), one can calculate $T_{\text {dyn1(i) }}$, which corresponds to a known log-spiral along which the static strengths, $\phi$ and $T_{\text {stat }}$, are fully mobilised. Unlike the procedure followed with equation (1), a maximisation process is not utilised for this step in the analyses; instead the critical log-spiral from the static case is used. This assumption is shown to be reasonable by the experimental results provided by Leshchinsky et al. (2009), and is also consistent with the failure surface assumptions that are made by FHWA (2009) and AASHTO (2007) for assessing the internal stability of earth-retaining structures under seismic loading conditions.

From the geometry shown in Fig. 1(b), one can calculate the angle where the radius intersects the equivalent reinforcement force, $\beta_{\mathrm{r}}$, from the relationship

$$
A \mathrm{e}^{-\psi_{\mathrm{d}} \beta_{\mathrm{r}}} \cos \beta_{\mathrm{r}}=A \mathrm{e}^{-\psi_{\mathrm{d}} \beta_{1}} \cos \beta_{1}-D
$$

As shown in Fig. 2, $T_{\text {dyn1 } 1}$ is determined for each time increment $(i)$ of the earthquake time series. For each step, its value should be checked to ensure that it does not exceed the pullout capacity. If a value of $T_{\mathrm{dyn} 1}$ greater than the pullout capacity is calculated, the displacement results from the model should not be used, as the scope of the current paper is limited to cases where pullout does not occur. In this case, the force in the reinforcement will be the pullout force.

For each time increment, the superimposed force in the reinforcement due to seismicity from the LE equations $\left(T_{\mathrm{md} 1}\right)$ can be determined as

$$
T_{\operatorname{md} 1(i)}=T_{\text {dyn1(i) }}-T_{\text {stat }}
$$

Note that $T_{\operatorname{md} 1(i)} \geqslant 0$ and

$$
\mathrm{d} T_{\operatorname{md} 1(i)}=T_{\operatorname{md} 1(i)}-T_{\operatorname{md}(i-1)}
$$

where $d T_{\mathrm{md} 1}$ is the incremental superimposed force in the reinforcement from the LE equations. Note that $d T_{\mathrm{md} 1}$ is determined by taking the difference between the superimposed force in the reinforcement in the current time increment from $\operatorname{LE}\left(T_{\operatorname{md} 1(i)}\right)$ and the prevailing value from the previous time step $\left(T_{\operatorname{md}(i-1)}\right)$.

Since LE analysis cannot directly relate displacement, stiffness and force in the reinforcement, an intermediate calculation tool is needed for this purpose. As will be discussed later in this paper, a set of FE analyses will be used to determine the displacement that corresponds to $\mathrm{d} T_{\mathrm{md} 1}$.

As shown in Fig. 1, $T_{\text {stat }}$ and $T_{\text {dyn1 }}$ act horizontally. Consequently, $T_{\mathrm{md} 1}$ and $\mathrm{d} T_{\mathrm{md} 1}$ also act horizontally. From these forces, it is possible to determine the horizontal component of incremental displacement, $\mathrm{d} \boldsymbol{\Delta} x_{1}$, using the FE charts that are provided later in this paper. The resultant displacement from the LE approach, $\mathrm{d} \boldsymbol{\Lambda}_{1}$, can be calculated using the equation (see Fig. 3)

$$
\mathrm{d} \boldsymbol{\Lambda}_{1(i)}=\frac{\mathrm{d} \boldsymbol{\Delta} x_{1(i)}}{\cos \beta_{\mathrm{r}}}
$$




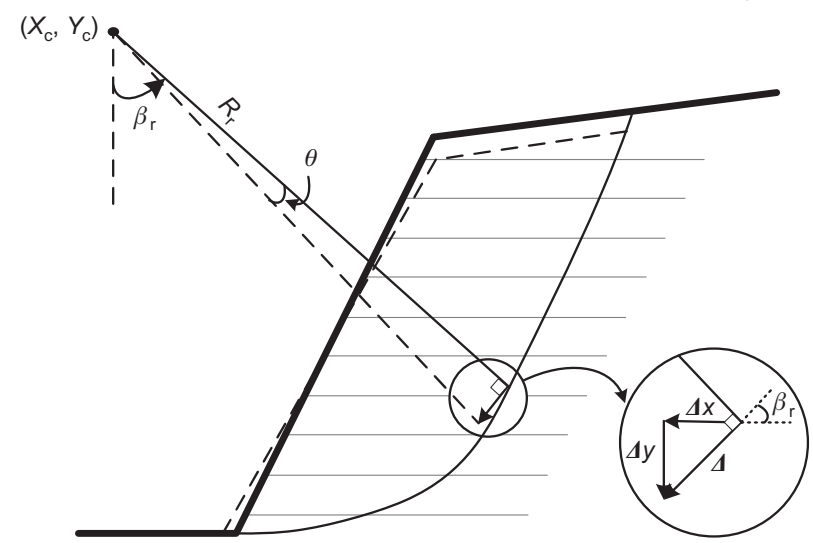

Fig. 3. Rotational failure of GRES, and seismic rotation and displacement components

\section{Step 2-2: Seismic reinforcement force and displacement from} integration

The force-based procedure that was explained in the previous section yields the upper-bound force that can be mobilised in the reinforcement, as determined by pseudostatic LE. For a given earthquake acceleration, this is the maximum force that can be induced in the reinforcement by the inertial response of the sliding body. However, since the body is accelerating for a limited time, it may not reach the force and displacement values that are determined using the LE equations. Therefore it is also necessary to assess the force that can be induced in the reinforcement by a given earthquake acceleration applied over a finite time increment. Following this approach, the force and displacement in the reinforcement can be determined using an integration procedure that is applied to the earthquake acceleration time series.

As shown in Fig. 2, for each time increment $i$, we have

$$
\boldsymbol{a}_{(i)}=a_{\mathrm{h}(i)} \cos \beta_{\mathrm{r}}-a_{\mathrm{v}(i)} \sin \beta_{\mathrm{r}}
$$

where $\boldsymbol{a}_{(i)}$ is the acceleration perpendicular to the radius leading to rotational acceleration, and $a_{\mathrm{h}(i)}$ and $a_{\mathrm{v}(i)}$ are the input horizontal and vertical accelerations, respectively ( $a_{\mathrm{h}}=K_{\mathrm{h}} \boldsymbol{g}, a_{\mathrm{v}}=K_{\mathrm{v}} \boldsymbol{g}$, and $\boldsymbol{g}=$ gravitational acceleration).

One can calculate angular velocity, $\boldsymbol{v}_{\omega}$, for each time increment as

$$
\begin{aligned}
\boldsymbol{v}_{\omega(i)} & =\sqrt{\frac{\boldsymbol{a}_{(i)}}{R}} \\
& =\sqrt{\frac{\boldsymbol{a}_{(i)}}{A \mathrm{e}^{-\psi_{\mathrm{d}} \beta_{\mathrm{r}}}}}
\end{aligned}
$$

Since the movement (i.e. rotation) is small and the change in $R$ is negligible, $R$ is constant in equation (8) during the seismic event. This assumption is proved to be reasonable by a set of large-scale shaking table test results provided by Leshchinsky et al. (2009), which show that in a rotational mode of failure the reinforcement holds the failure mass coherent, and internal deformations are not significant.

The perpendicular velocity of the rotating mass, $\boldsymbol{v}$, for each time increment is equal to

$$
\begin{aligned}
\boldsymbol{v}_{(i)} & =R \boldsymbol{v}_{\omega(i)} \\
& =\sqrt{\boldsymbol{a}_{(i)} A \mathrm{e}^{-\psi_{\mathrm{d}} \beta_{\mathrm{r}}}}
\end{aligned}
$$

and the incremental resultant displacement from the integration procedure, $\mathrm{d} \boldsymbol{\Delta}_{2}$, is

$$
\mathrm{d} \boldsymbol{\Delta}_{2(i)}=\frac{\boldsymbol{v}_{(i)}-\boldsymbol{v}_{(i-1)}}{2} \mathrm{~d} t
$$

where $\mathrm{d} t=t_{i}-t_{i-1}$.

The horizontal component of displacement from the integration approach, $\Delta x_{2}$, can be determined using the equation

$$
\boldsymbol{\Delta} x_{2(i)}=\left(\mathrm{d} \boldsymbol{\Delta}_{2(i)}+\boldsymbol{\Delta}_{(i-1)}\right) \cos \beta_{\mathrm{r}}
$$

Note that the horizontal component of displacement from the integration approach $\left(\boldsymbol{\Delta} x_{2}\right)$ is determined by summation of the incremental displacement in the reinforcement in the current time increment from integration $\left(\mathrm{d} \boldsymbol{\Delta}_{2(i)}\right)$ and the prevailing value from the previous time step $\left(\boldsymbol{\Delta}_{(i-1)}\right)$.

For the next step in the analysis, a series of curves that relate the force and displacement in the reinforcement prior to pullout is used to determine the dynamic force $\left(T_{\text {dyn2 } 2}\right)$ that corresponds to the calculated horizontal component of displacement from the integration approach $\left(\boldsymbol{\Delta} x_{2}\right)$. These curves were developed using FE analysis, following the procedure that is discussed in more detail later in this paper.

The superimposed force in the reinforcement $\left(T_{\operatorname{md} 2}\right)$ and incremental superimposed force in the reinforcement $\left(\mathrm{d} T_{\mathrm{md} 2}\right)$ from the integration procedure are calculated using the equations

$$
\begin{aligned}
& T_{\mathrm{md} 2(i)}=T_{\operatorname{dyn} 2(i)}-T_{\text {stat }} \\
& \mathrm{d} T_{\operatorname{md} 2(i)}=T_{\operatorname{md} 2(i)}-T_{\operatorname{md}(i-1)}
\end{aligned}
$$

In these analyses, it is assumed that the reinforcement will not experience any retraction during the seismic event. Consequently, negative values of $T_{\mathrm{md} 2}$ will be set to zero (Fig. 2).

In a similar fashion to the LE approach, the incremental superimposed force in the reinforcement $\left(\mathrm{d} T_{\mathrm{md} 2}\right)$ is calculated by taking the difference between the superimposed force in the reinforcement in the current time increment from the integration approach $\left(T_{\operatorname{md} 2(i)}\right)$ and the prevailing value from the previous time step $\left(T_{\operatorname{md}(i-1)}\right)$.

\section{Step 3: Seismic displacement}

At each step in an acceleration time series, the LE approach (step 2-1, equations (2)-(6)) can be used to determine the upper-bound force and associated displacement that can be mobilised in the reinforcement. In addition, the integration approach described herein (step 2-2, equations (7)-(13)) provides a means to calculate the displacement and associated force that can be induced in the reinforcement over a finite time increment. The smaller of the forces yielded from these two conditions controls the seismically induced force and displacement in the reinforcement for each time increment. In the analysis, this is determined using the following calculation process (Fig. 2).

$$
\begin{aligned}
& \mathrm{d} T_{\operatorname{md}(i)}=\min \left(\mathrm{d} T_{\operatorname{md} 1(i)} ; \mathrm{d} T_{\operatorname{md} 2(i)}\right) \\
& \mathrm{d} \boldsymbol{\Lambda}_{(i)}=\min \left(\mathrm{d} \boldsymbol{\Delta}_{1(i)} ; \boldsymbol{d}_{2(i)}\right)
\end{aligned}
$$

where $\mathrm{d} T_{\mathrm{md}}$ is the prevailing incremental superimposed force in the reinforcement, and $\mathrm{d} \boldsymbol{\Delta}$ is the prevailing incremental displacement. The summation of the incremental displacements and induced forces in the reinforcement over the entire time series analysis provides the necessary information to guide the design of a GRES. This is achieved by performing the following calculations for each time increment $(i)$.

$$
\begin{aligned}
& T_{\operatorname{md}(i)}=\mathrm{d} T_{\operatorname{md}(i)}+T_{\operatorname{md}(i-1)} \\
& \boldsymbol{\Delta}_{(i)}=\mathrm{d} \boldsymbol{\Delta}_{(i)}+\boldsymbol{\Delta}_{(i-1)}
\end{aligned}
$$


In addition to the resultant displacement along the shear plane $(\boldsymbol{\Delta})$, it can also be instructive to look at the total angular rotation $(\theta)$ that occurs as a result of shaking (see Fig. 3). This can be achieved by performing the following calculation for each time increment $(i)$.

$$
\begin{aligned}
\theta_{(i)} & =\frac{\boldsymbol{\Delta}_{(i)}}{R} \\
& =\frac{\boldsymbol{\Delta}_{(i)}}{A \mathrm{e}^{-\psi_{\mathrm{d}} \beta_{\mathrm{r}}}}
\end{aligned}
$$

From the geometry shown in Fig. 3, the horizontal $(\Delta x)$ and vertical $(\Delta y)$ components of the resultant displacement can be calculated using the equations

$$
\begin{aligned}
\Delta x_{(i)} & =R \theta_{(i)} \sin \beta_{\mathrm{r}} \\
& =A \mathrm{e}^{-\psi_{\mathrm{d}} \beta_{\mathrm{r}}} \theta_{(i)} \sin \beta_{\mathrm{r}} \\
\Delta y_{(i)} & =R \theta_{(i)} \cos \beta_{\mathrm{r}} \\
& =A \mathrm{e}^{-\psi_{\mathrm{d}} \beta_{\mathrm{r}}} \theta_{(i)} \cos \beta_{\mathrm{r}}
\end{aligned}
$$

At the end of a given shaking event, we have a certain seismic-induced superimposed force, $T_{\mathrm{md}}$, that remains in the reinforcement, and a corresponding displacement. Over time, this superimposed force will relax to its original value. However, the displacement will remain permanent.

The displacement-based design approach presented herein is not intended to calculate the displacement of GRESs for analysis purposes, but will provide the reinforcement strength and pullout resistance for design purposes. The design approach that is presented ensures that the reinforcement will not be ruptured - that is, its stretching in terms of GRES displacement will always be small, or else the reinforcement will be ruptured or pulled out.

It is widely recognised that the shear strength of soil under seismic conditions can be degraded by a shaking event. To account for this degradation, the authors recommend the use of $\phi_{\text {residual }}$ (or $\phi_{\mathrm{cv}}$ ) for design; this contrasts with the recommendation made by FHWA (2009) and AASHTO (2007) to use $\phi_{\text {peak }}$ for design purposes (although AASHTO limits $\phi$ to $40^{\circ}$ ). The authors consequently recommend the use of $\phi_{\mathrm{cv}}$ for use with the design approach that is proposed in this paper. The use of $\phi_{\mathrm{cv}}$ (or $\phi_{\text {residual }}$ ) in the seismic design of reinforced earth structures has been advocated by a number of researchers (e.g. Bolton, 1986; Jewell, 1996; Liu \& Ling, 2012) to account for the strength degradation and strain-softening of backfill soil that can occur during a seismic event. Further discussion regarding the use of peak against residual shear strength for GRES design purposes can be found in the papers by Leshchinsky (2001) and Liu \& Ling (2012).

\section{RELATIONSHIP BETWEEN FORCE AND DISPLACEMENT IN EQUIVALENT GEOSYNTHETIC LAYER}

As explained in the previous sections, an intermediatestage tool is needed that can directly relate displacement, stiffness and force in the reinforcement. For a given reinforcement stiffness, this tool will be utilised in the current approach to find the horizontal displacement $\left(\Delta x_{1}\right)$ that corresponds to the superimposed force calculated from the LE equations $\left(T_{\mathrm{md} 1}\right)$. In parallel, the tool will also be employed to determine the dynamic force $\left(T_{\mathrm{dyn} 2}\right)$ that corresponds to the horizontal displacement calculated using the integration process $\left(\boldsymbol{\Delta} x_{2}\right)$. This relationship can be found by calibrating the model based on experimental test results (e.g. Paulsen \& Kramer, 2004) or by using numerical tools. In this study, two-dimensional FE analyses were performed using the program ABAQUS (2007) to develop a series of force-displacement curves.

As shown in Fig. 1(b), displacement of the sliding mass (which is assumed to be a rigid body) becomes feasible only when the anchored reinforcement stretches. The reinforcement can stretch from pullout (slippage between the geosynthetic and surrounding soil), from true deformation (strain in the geosynthetic itself), or from both mechanisms acting together. In this study, a series of FE analyses was performed to simulate the behaviour of a 'long' geosynthetic that is stretched to simulate force-displacement behaviour of a geosynthetic that is not experiencing pullout. So, in the FE analysis, a pullout test with very long reinforcement was simulated. Fig. 4, which is not drawn to scale, shows a schematic view of the model that was used in the analyses. If the reinforcement is embedded to a sufficiently long length, its rear end will not move (i.e. it will not be able 'to feel' the load applied at the intersection with the log-spiral).

As shown in Fig. 4, FE analyses were used to simulate the behaviour of a very long equivalent geosynthetic layer that was embedded between two confining soil layers. The geosynthetic was modelled using a uniform mesh comprising two-node linear two-dimensional truss elements that obeyed linear elastic behaviour. The behaviour of the interface between the geosynthetic and the reinforced soil was simulated using interface elements that utilised a 'penalty' formulation approach (ABAQUS, 2007).

The geosynthetic/soil interface angle was assumed to be given by $\tan \delta=0.8 \tan \phi$, where $\delta$ is the interface friction angle. The soil layers surrounding the geosynthetic were modelled using four-node bilinear plane-strain quadrilateral elements that utilised the Mohr-Coulomb constitutive model. Poisson's ratio was assumed to be $0 \cdot 3$ for both the reinforced soil and the equivalent geosynthetic layer. The Young's modulus of the reinforced soil was assumed to be $35 \mathrm{MPa}$. Parametric studies using this model showed that the Poisson's ratios that were chosen for the geosynthetic and surrounding soil layers had little or no impact on the model results within the displacement range of interest.

In the FE analyses, incremental pullout displacements were applied to one end of the geosynthetic reinforcement layer at a very slow rate $(1 \mathrm{~mm} / \mathrm{min})$, causing the reinforcement to stretch along its length. The reaction force at the front edge of the geosynthetic (where the displacement was applied) was monitored, and the resulting data were used to plot the associated curve of pullout force against displacement. For each displacement increment that was applied, the reinforcement strains the most at the point of application, with the strain decreasing along the length of the reinforcement as load is shed into the surrounding soil layers. For sufficiently long reinforcement, there is zero reinforcement strain at the far end of the layer. At a given location, the load carried by the reinforcement can be determined by

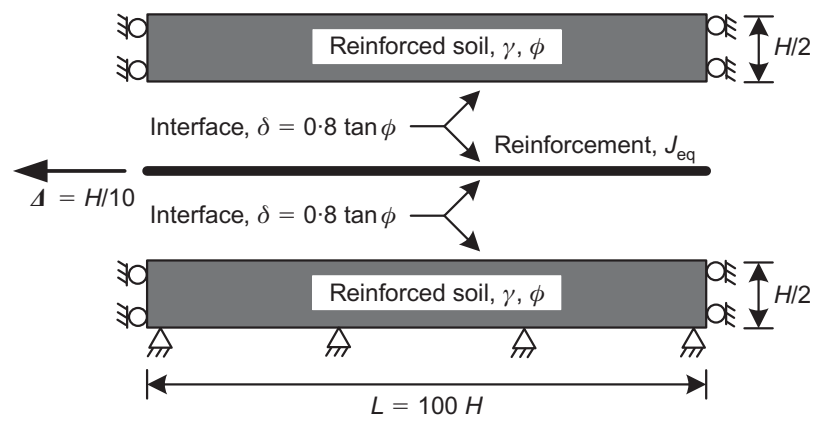

Fig. 4. Schematic view of the FE model utilised for pullout simulation 
multiplying the local strain by the modulus of the reinforcement $(J)$.

Numerous pullout simulations were performed over a wide variety of input parameters. However, as space is limited herein, only the results for two friction angles of the reinforced soil $\left(\phi=30^{\circ}\right.$ and $\left.40^{\circ}\right)$ and two different heights $(H=3 \mathrm{~m}$ and $6 \mathrm{~m})$ are provided (Figs 5 and 6$)$. Results are presented for variations in the geosynthetic modulus $(J)$ over a range from 300 to $3000 \mathrm{kN} / \mathrm{m}$ per $\mathrm{m}$. The results of the FE simulation for $H=3 \mathrm{~m}$ and $H=6 \mathrm{~m}$ are illustrated in Figs 5 and 6 respectively.

In Figs 5 and 6, an equivalent normalised modulus of geosynthetic, $J_{\text {eq }}$, was used, which is equal to

$$
J_{\text {eq }}=\frac{n J}{\gamma H^{2}}
$$

where $n$ is the number of geosynthetic layers in a GRES, $J$ is the geosynthetic modulus, $\gamma$ is the unit weight of the reinforced soil, and $H$ is the height of the earth structure.

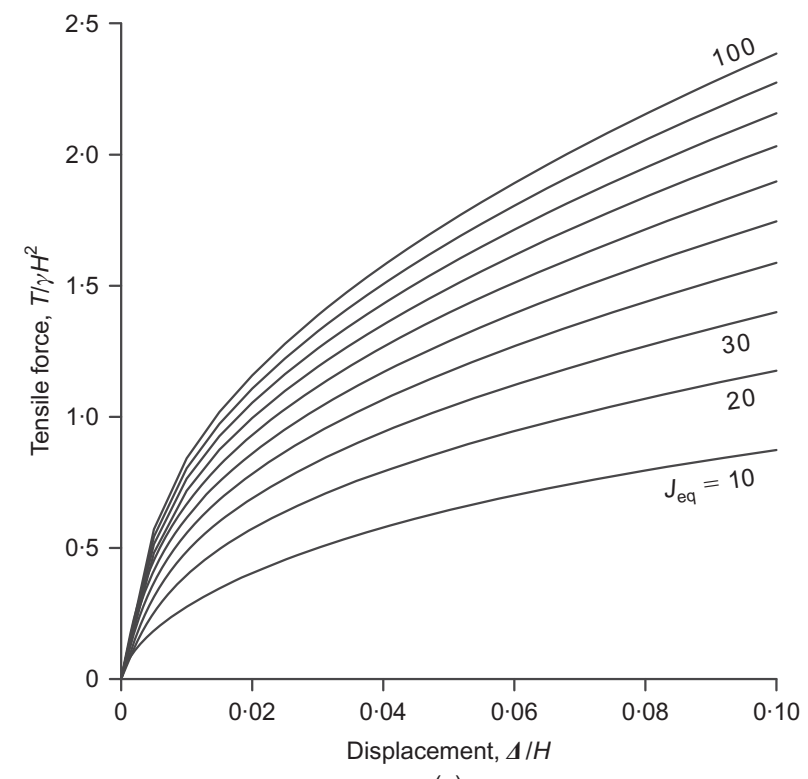

(a)

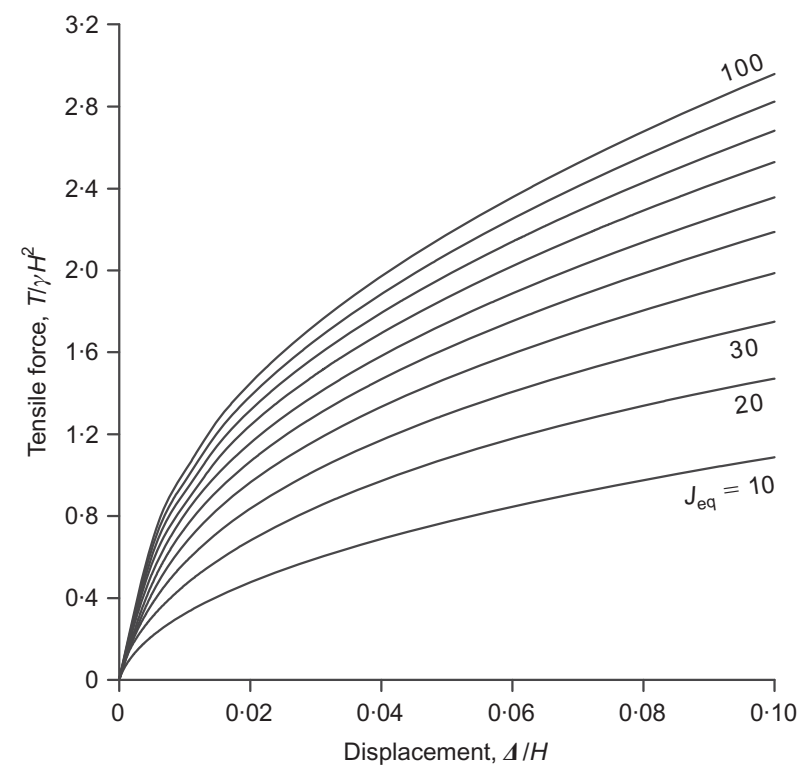

(b)

Fig. 5. Tensile force against displacement for $H=3 \mathrm{~m}$ from the FE pullout simulation: (a) $\phi=30^{\circ}$; (b) $\phi=40^{\circ}$

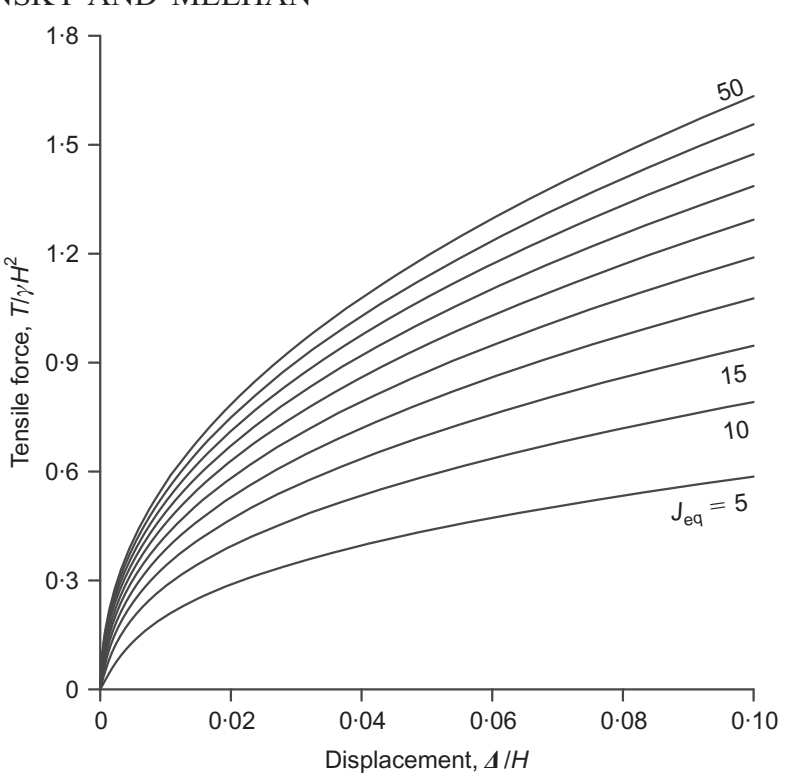

(a)

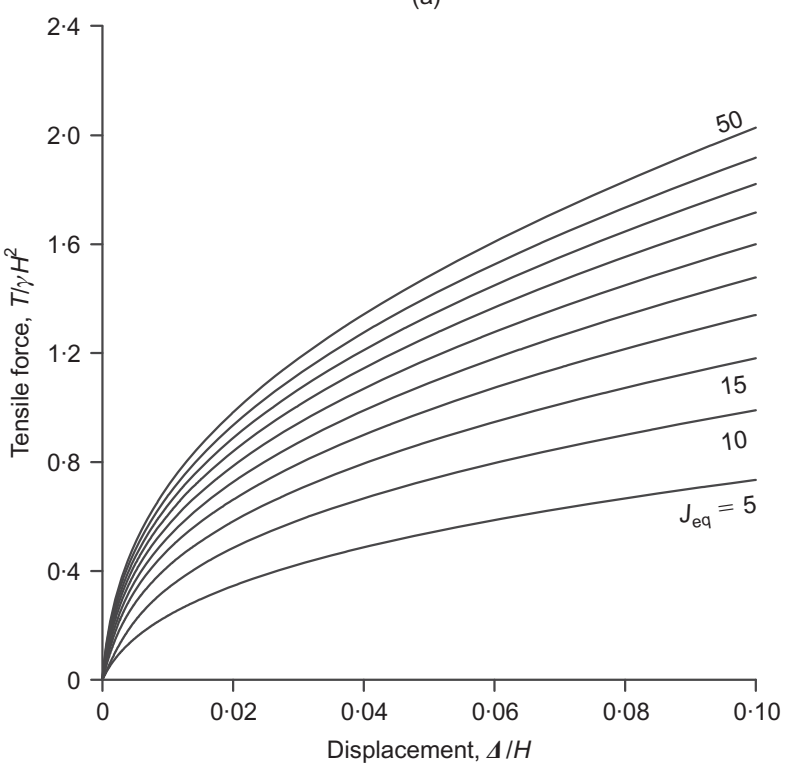

(b)

Fig. 6. Tensile force against displacement for $H=6 \mathrm{~m}$ from the FE pullout simulation: (a) $\phi=30^{\circ}$ (b) $\phi=40^{\circ}$

The geosynthetic modulus can be calculated by multiplying Young's modulus, $E$, by the geosynthetic thickness.

The authors would like to reiterate that the FE analysis utilised in the current study is just one of several possible ways to develop force-displacement curves (e.g. experimental data, linear spring-slider models or more complex FE models). As explained previously, these curves act as an auxiliary tool within the proposed analytical framework.

\section{ILLUSTRATIVE DESIGN EXAMPLE}

The following example shows how the methodology that is presented can be utilised for the seismic design of a GRES. For this example, a strong ground motion recorded at the Kakogawa station during the Kobe (1995) earthquake $\left(M_{\mathrm{w}}=6.9\right)$ is used (Fig. 7). The peak ground acceleration (PGA) for this strong motion is $0 \cdot 345 \mathrm{~g}$. As shown, just the horizontal component is considered in the current example. In order to design a GRES to resist this applied ground shaking, the approach that is presented herein will be utilised to determine the superimposed force 


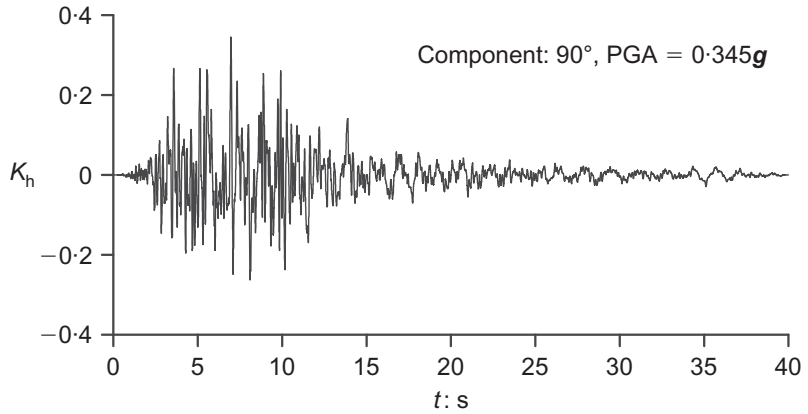

Fig. 7. Strong ground motion recorded at Kakogawa station during Kobe (1995) earthquake $\left(M_{\mathrm{w}}=6.9\right)$

in the reinforcement due to seismicity $\left(T_{\mathrm{md}}\right)$, the resultant displacement along the shear plane $(\Delta)$, and the total rotation $(\theta)$. A reinforcement force distribution function will then be used to determine the maximum unfactored reinforcement force under the static condition $\left(T_{\max -j}\right)$ and the superimposed force due to seismicity $\left(T_{\mathrm{md}-j}\right)$ in each of the reinforcement layers.

For purposes of this example, the following structure is considered: a wrapped-face GRES with $\omega=0^{\circ}$, a horizontal crest, $H=6 \mathrm{~m}$, and $S_{\mathrm{v}}=0.5 \mathrm{~m}$, where $S_{\mathrm{v}}$ is the uniform vertical spacing between the reinforcement layers. The spacing from the base to the first layer is taken to be $0 \cdot 5 S_{\mathrm{v}}$, which leads to a total of 12 reinforcement layers $(n=12)$. Wrapped facing does not generate toe resistance, $R_{\mathrm{h}}$, and consequently $R_{\mathrm{h}}$ is zero in this example. The contributory area of each layer is taken as the vertical height of the wrapped portion, and is consequently equal to $0.5 \mathrm{~m}$. For calculating $T_{\max }$ at each reinforcement layer, the location of each geosynthetic layer is approximated to be at the middle of the contributory area. A uniform $(D=H / 2)$ distribution function was chosen to distribute the force among the reinforcement layers. For the reinforced soil, two types of cohesionless backfill material were examined $\left(\phi=30^{\circ}\right.$ and $40^{\circ}$ ), which were both assumed to have a $\gamma=20 \mathrm{kN} / \mathrm{m}^{3}$. For purposes of design, two types of geosynthetic were examined, with different stiffnesses ( $J=300$ and $3000 \mathrm{kN} / \mathrm{m}$ per m).

To solve this problem, the step-by-step procedure shown in Fig. 2 was carried out. In order to select the appropriate FE force-displacement curves for use in this design process, the equivalent reinforcement stiffness for each type of reinforcement is calculated based on the reinforcement type. Using a geosynthetic with $J=300 \mathrm{kN} / \mathrm{m}$ per $\mathrm{m} J_{\text {eq }}$ will be

$$
\begin{aligned}
J_{\text {eq }} & =\frac{n J}{\gamma H^{2}} \\
& =\frac{12 \times 300(\mathrm{kN} / \mathrm{m} \text { per m })}{20\left(\mathrm{kN} / \mathrm{m}^{3}\right) \times 6^{2}\left(\mathrm{~m}^{2}\right)} \\
& =5 \mathrm{~m}^{-1}
\end{aligned}
$$

Similarly, $J_{\text {eq }}=50 \mathrm{~m}^{-1}$ for a geosynthetic with $J=3000 \mathrm{kN} / \mathrm{m}$ per $\mathrm{m}$.

The failure surfaces for the different $\phi$ values that were examined are shown in Fig. 8. Values of $T_{\mathrm{md}}, \boldsymbol{\Delta}$ and $\theta$ for friction angles of $30^{\circ}$ and $40^{\circ}$ are shown in Figs 9 and 10 respectively. Table 1 provides a summary of the results for the cases that were investigated. As noted before, a uniform distribution function $(D=H / 2)$ was employed in this example, and the maximum tensile force under the static condition for the $j$ th reinforcement layer $\left(T_{\max -j}\right)$, and the superimposed force due to seismicity for the $j$ th reinforcement layer $\left(T_{\mathrm{md}-j}\right)$ were determined accordingly.

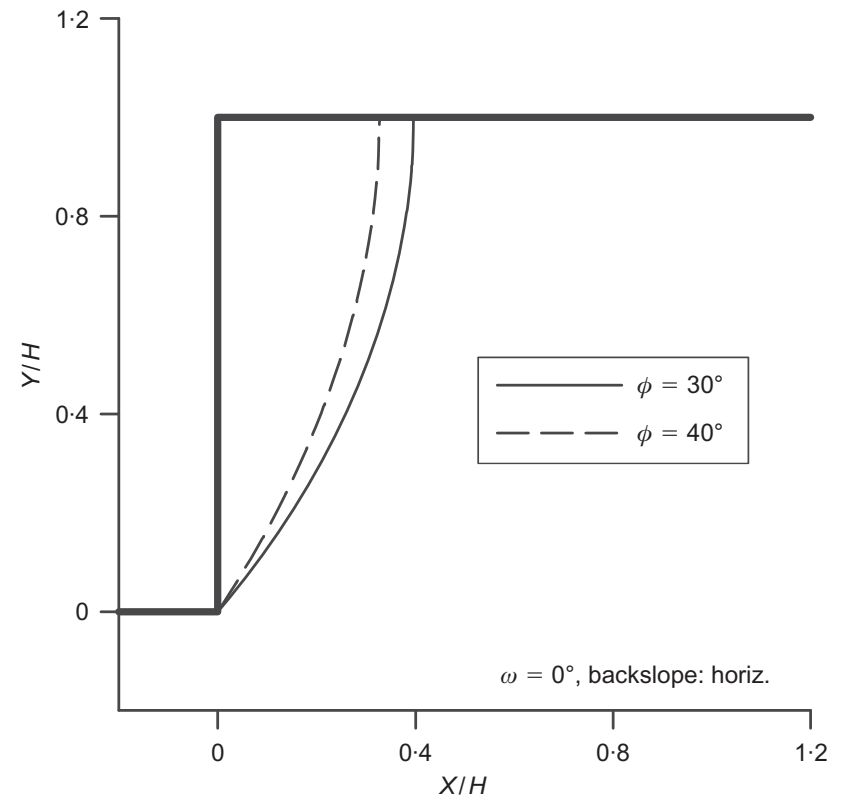

Fig. 8. Failure surfaces for design example using $\phi=30^{\circ}$ and $40^{\circ}$
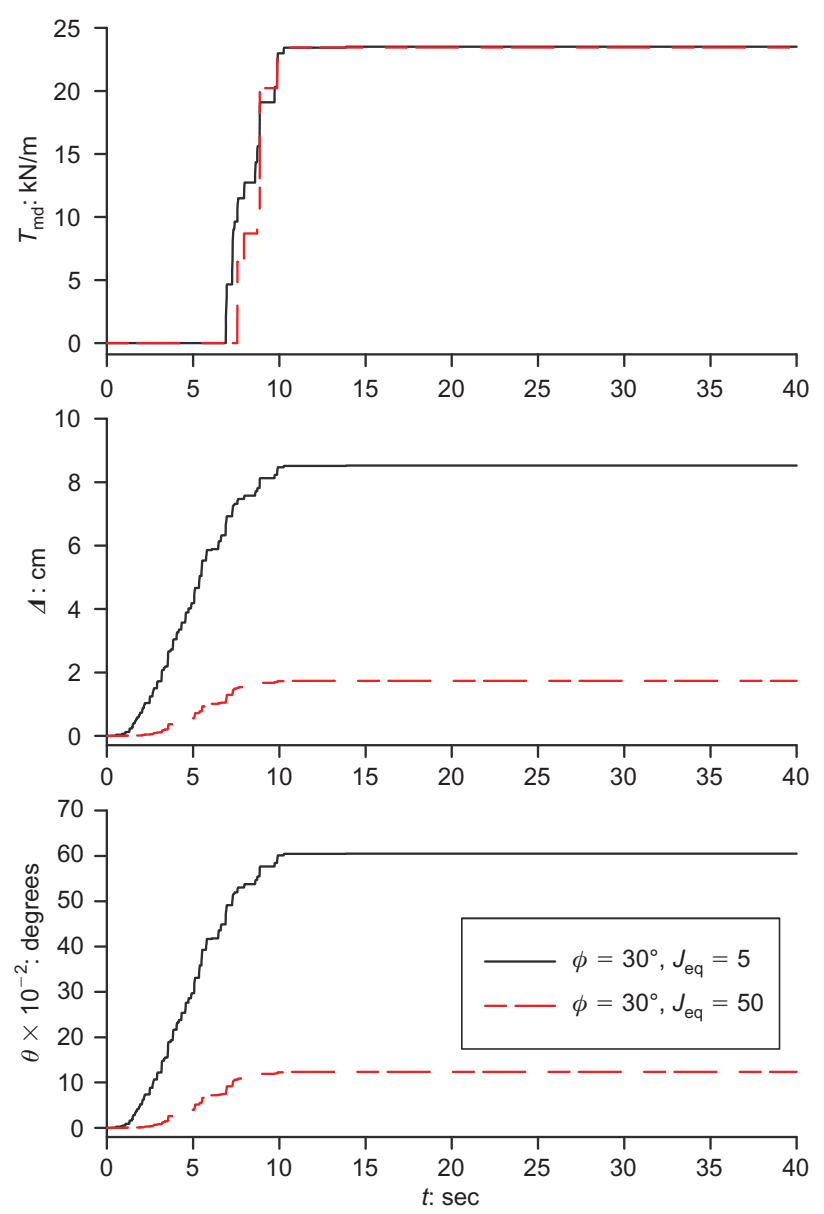

Fig. 9. Superimposed reinforcement force due to seismicity, $T_{\mathrm{md}}$, displacement, $\Delta$, and rotation, $\theta$, for design example using $\phi=30^{\circ}$

As explained previously, the current approach is intended to determine the value of $T_{\mathrm{md}}$ that corresponds to a certain seismic displacement. For comparison purposes, the $T_{\mathrm{md}}$ values calculated using the proposed displacement-based approach are compared with those obtained using a pseudostatic approach. Following a pseudo-static methodology, the seismically induced force in the reinforcement can be calculated by multiplying the weight of the failure mass $(W)$ by 


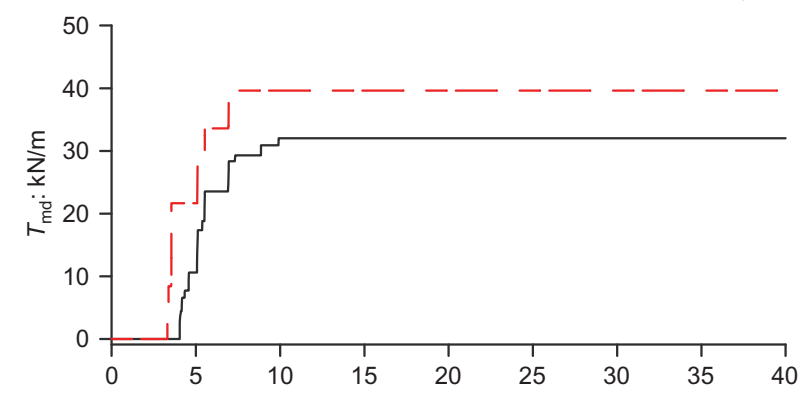

\section{SUMMARY AND CONCLUSIONS}

The significant importance of post-earthquake serviceability of GRESs has led to an increasing trend towards the use of displacement-based design methods within the past decade. This paper presents a new analytical-numerical framework for the displacement-based design of GRESs, which assesses the potential for earthquake-induced displacements via a rotational failure mechanism. While the majority of the existing analytical approaches for displacement-based seismic design of GRESs are developed by considering only a translational mode of failure (i.e. external sliding stability), the proposed approach provides a rational framework for assessing the seismic displacement of GRESs due to internal stability (rotational movement). This failure mechanism may control the required tensile strength of the reinforcement for GRESs. Moreover, an internal rotational failure mode can degenerate to a translational one should it be more critical; however, the reverse is not true, which makes rotational failure a more generic mechanism.

For design purposes, in order to determine the superimposed force in the reinforcement due to seismicity and its associated displacement, the proposed approach examines two limiting conditions.

(a) The upper-bound force that can be mobilised in the reinforcement, as determined by pseudo-static LE. For a given earthquake acceleration, this would be the maximum force that can be induced in the reinforcement by the inertial response of the sliding body.

(b) The force that can be induced in the reinforcement by a given earthquake acceleration applied over a finite time increment. This second limiting condition examines the time limitation effect, which accounts for the transient characteristics of the applied ground motion.

Fig. 10. Superimposed reinforcement force due to seismicity, $T_{\mathrm{md}}$, displacement, $\Delta$, and rotation, $\theta$, for design example using $\phi=40^{\circ}$

the pseudo-static coefficient $\left(K_{\mathrm{h}}=\mathrm{PGA} / \mathrm{g}\right)$. For $\phi=30^{\circ}$, utilising the geometry of the failure surface shown in Fig. 8 and a PGA of $0.345 \mathrm{~g}$ (Fig. 7), one can calculate the seismically induced force in the reinforcement from a pseudo-static approach as

$$
\begin{aligned}
W K_{\mathrm{h}} & =A H^{2} \gamma K_{\mathrm{h}} \\
& =0.2673 \times 6^{2}\left(\mathrm{~m}^{2} / \mathrm{m}\right) \times 20\left(\mathrm{kN} / \mathrm{m}^{2}\right) \times 0.345 \\
& =66.4 \mathrm{kN} / \mathrm{m}
\end{aligned}
$$

where $A$ is the area of the failure mass determined from Fig. 8 , and the other variables are as defined previously. Using a similar calculation for $\phi=40^{\circ}, W K_{\mathrm{h}}=54 \cdot 1 \mathrm{kN} / \mathrm{m}$. As shown in Table 1, for the cases that were examined in this example, the proposed displacement-based approach yields $T_{\mathrm{md}}$ values that are $36 \%$ to $182 \%$ smaller than those that result from a pseudo-static approach.

The smaller of the forces yielded from these two conditions controls the seismically induced force and displacement in the reinforcement for each time increment. In order to relate the force and displacement in the geosynthetic reinforcement, a set of pullout simulations was performed using FE analysis for various geosynthetic stiffnesses. The summation of the incremental displacements and induced forces in the reinforcement over the entire time series analysis provides the necessary information to guide the design of a GRES.

Using a Kobe earthquake record, a design example was solved to illustrate the application of the proposed method. The superimposed force due to seismicity, seismic displacement, and seismic rotation were calculated for various soil friction angles and geosynthetic stiffnesses. For each case that was examined, a uniform distribution function is used to determine the required unfactored geosynthetic strength in the individual reinforcement layers. For the examples that were provided, the proposed displacement-based approach yielded superimposed forces in the reinforcement due to seismicity that were $36 \%$ to $182 \%$ smaller than those that resulted from a pseudo-static approach.

Table 1. Summary of results for design example

\begin{tabular}{l|c|c|c|c|c|c|c|c|c|c}
\hline Case & $\phi:$ degrees & $\begin{array}{c}J: \mathrm{kN} / \mathrm{m} \\
\text { per } \mathrm{m}\end{array}$ & $J_{\mathrm{eq}}: \mathrm{m}^{-1}$ & $T_{\text {stat }}: \mathrm{kN} / \mathrm{m}$ & $W K_{\mathrm{h}}: \mathrm{kN} / \mathrm{m}$ & $T_{\mathrm{md}}: \mathrm{kN} / \mathrm{m}$ & $T_{\text {dyn }}: \mathrm{kN} / \mathrm{m}$ & $\begin{array}{c}T_{\text {max }-j}+T_{\mathrm{md}-j}: \\
\mathrm{kN} / \mathrm{m}\end{array}$ & $\begin{array}{c}\boldsymbol{\Delta}: \mathrm{cm} \\
\theta \times 10^{-2}: \\
\text { degrees }\end{array}$ \\
\hline 1 & 30 & 300 & 5 & $130 \cdot 1$ & $66 \cdot 4$ & $23 \cdot 5$ & $153 \cdot 6$ & $12 \cdot 8$ & $8 \cdot 5$ & $60 \cdot 5$ \\
2 & 30 & 3000 & 50 & $130 \cdot 1$ & $66 \cdot 4$ & $23 \cdot 5$ & $153 \cdot 6$ & $12 \cdot 8$ & $1 \cdot 7$ & $12 \cdot 3$ \\
3 & 40 & 300 & 5 & $83 \cdot 0$ & $54 \cdot 1$ & $32 \cdot 0$ & $115 \cdot 0$ & $9 \cdot 6$ & $3 \cdot 9$ & $26 \cdot 2$ \\
4 & 40 & 3000 & 50 & $83 \cdot 0$ & $54 \cdot 1$ & $39 \cdot 6$ & $122 \cdot 6$ & $10 \cdot 2$ & $1 \cdot 1$ & $7 \cdot 2$ \\
\hline
\end{tabular}




\section{ACKNOWLEDGEMENTS}

This material is based upon work supported by the National Science Foundation under Grant No. CMMI0844836. This National Science Foundation grant partially supported the first and third authors in conjunction with their work on this project. The authors would also like to extend their thanks to Mr Fan Zhu for his valuable assistance with the formulation and programming that was conducted during this project.

\section{NOTATION}

A log-spiral constant

$\boldsymbol{a}_{(i)}$ acceleration perpendicular to radius of log-spiral failure surface at time increment $i$

$a_{\mathrm{h}(i)}, a_{\mathrm{v}(i)}$ horizontal and vertical accelerations at time increment $i$

$D$ elevation of line of action of resultant reinforcement force, measured from toe of structure

E Young's modulus

g gravitational acceleration

$H$ height of slope

$i$ increment in earthquake acceleration time series

$J, J_{\text {eq }}$ geosynthetic modulus, equivalent geosynthetic modulus

$K_{\mathrm{h}(i)}, K_{\mathrm{v}(i)}$ horizontal and vertical seismic coefficients at time increment $i$

$n$ number of geosynthetic layers

$q$ uniform surcharge acting on crest

$R \quad \log$-spiral radius

$R_{\mathrm{h}}$ horizontal resistance of facing at bottom of slope

$R_{\mathrm{r}}$ radius where the trace of log-spiral intersects the equivalent reinforcement force

$S_{\mathrm{v}} \quad$ uniform vertical spacing between reinforcement layers

$T_{\text {dyn }(i)}, T_{\operatorname{dyn} 1(i)}, T_{\operatorname{dyn} 2(i)}$ seismic force in reinforcement at time increment $i$ (prevailing value), from limit equilibrium equations and from integration approach respectively

$\mathrm{d} T_{\operatorname{dyn}(i)}, \mathrm{d} T_{\operatorname{dyn} 1(i)}, \mathrm{d} T_{\operatorname{dyn} 2(i)}$ incremental seismic force in reinforcement at time increment $i$ (prevailing value), value from limit equilibrium equations, and value from integration approach respectively

$T_{\max -j}$ maximum tensile force under static condition for $j$ th reinforcement layer

$T_{\operatorname{md}(i)}, T_{\operatorname{md} 1(i)}, T_{\operatorname{md} 2(i)}$ superimposed force in the reinforcement due to seismicity at time increment $i$ (prevailing force), from limit equilibrium equations and from integration approach respectively

$\mathrm{d} T_{\operatorname{md}(i)}, \mathrm{d} T_{\operatorname{md} 1(i)}, \mathrm{d} T_{\operatorname{md} 2(i)}$ incremental superimposed force in reinforcement due to seismicity at time increment $i$ (prevailing value), value from limit equilibrium equations, and value from integration approach respectively

$T_{\text {md-j }} \quad$ superimposed force due to seismicity for $j$ th reinforcement layer

$T_{\text {stat }}$ resultant reinforcement force under static loading

$d \mathrm{t}$ time step in earthquake acceleration time series; $\mathrm{d} t=t_{(i)}-t_{(i-1)}$

$\boldsymbol{v}_{(i)}$ perpendicular velocity of rotating mass at time increment $i$

$\boldsymbol{v}_{\omega(i)}$ angular velocity of rotating mass at time increment $i$

$W$ weight of failure mass

$X_{\mathrm{c}}, Y_{\mathrm{c}}$ coordinates of pole of log-spiral in Cartesian coordinate system $\alpha$ backslope angle of crest

$\beta_{\mathrm{r}} \quad$ angle of rotation to point where radius intersects equivalent reinforcement force

$\beta_{1}, \beta_{2}$ angle of rotation to points where logspiral enters and exits slope

$\gamma \quad$ unit weight of soil

$\boldsymbol{\Delta}_{(i)}, \boldsymbol{\Delta}_{1(i)}, \boldsymbol{\Delta}_{2(i)}$ resultant seismic displacement at time increment $i$ (prevailing value), value from limit equilibrium equations, and value from integration approach respectively

$\mathrm{d} \boldsymbol{\Delta}_{(i)}, \mathrm{d} \boldsymbol{\Delta}_{1(i)}, \mathrm{d} \boldsymbol{\Delta}_{2(i)}$ incremental resultant seismic displacement at time increment $i$ (prevailing value), value from limit equilibrium equations, and value from integration approach respectively

$\Delta x_{(i)}, \Delta x_{1(i)}, \Delta x_{2(i)}$ horizontal component of seismic displacement at time increment $i$ (prevailing value), value from limit equilibrium equations, and value from integration approach respectively

$\mathrm{d} \boldsymbol{\Delta} x_{(i)}, \mathrm{d} \boldsymbol{\Delta} x_{1(i)}, \mathrm{d} \boldsymbol{\Delta} x_{2(i)}$ incremental horizontal component of seismic displacement at time increment $i$ (prevailing value), value from limit equilibrium equations, and value from integration approach respectively

$\Delta y_{(i)}, \Delta y_{1(i)}, \Delta y_{2(i)}$ vertical component of seismic displacement at time increment $i$ (prevailing value), value from limit equilibrium equations, and value from integration approach respectively

$\mathrm{d} \boldsymbol{\Delta} y_{(i)}, \mathrm{d} \boldsymbol{\Delta} y_{1(i)}, \mathrm{d} \boldsymbol{\Delta} y_{2(i)}$ incremental vertical component of seismic displacement at time increment $i$ (prevailing value), value from limit equilibrium equations, and value from integration approach respectively

$\theta_{(i)}, \theta_{1(i)}, \theta_{2(i)} \quad$ seismically induced rotation at time increment $i$ (prevailing value), from limit equilibrium equations and from integration approach respectively

$\mathrm{d} \theta_{(i)}, \mathrm{d} \theta_{1(i)}, \mathrm{d} \theta_{2(i)}$ incremental seismically induced rotation at time increment $i$ (prevailing value), value from limit equilibrium equations, and value from integration approach respectively

$\phi_{\mathrm{cv}}$ constant-volume angle of friction

$\phi_{\text {design }}$ design internal angle of friction

$\phi_{\text {peak }}$ peak angle of friction

$\phi_{\text {residual }}$ residual angle of friction

$\psi_{\mathrm{d}} \tan \phi$

$\omega$ slope batter (slope face inclination $=90^{\circ}-\omega$ )

\section{REFERENCES}

AASHTO (2007). AASHTO LRFD bridge design specifications, 4th edn. Washington, DC, USA: American Association of State Highway and Transportation Officials.

ABAQUS (2007). ABAQUS user's manuals, Version 6.7. Pawtucket, RI, USA: Hibbitt, Karlson and Sorensen Inc.

Ausilio, E., Conte, E. \& Dente, G. (2000). Seismic stability analysis of reinforced slopes. Soil Dynam. Earthquake Engng 19, No. 3, $159-172$.

Bolton, M. D. (1986). The strength and dilatancy of sands. Géotechnique 36, No. 1, 65-78, http://dx.doi.org/10.1680/geot. 1986.36.1.65

Cai, Z. \& Bathurst, R. J. (1996). Seismic-induced permanent displacement of geosynthetic reinforced segmental retaining walls. Can. Geotech. J. 33, No. 6, 937-955.

FHWA (2009). Mechanically stabilized earth walls and reinforced soil slopes design and construction guidelines, Volume I, Publication No. FHWA-NHI-10-025 (authored by R. R. Berg, B. R. Christopher and N. C. Samtani). Washington, DC, USA: Federal Highway Administration, US Department of Transportation.

Huang, C. C., Chou, L. H. \& Tatsuoka, F. (2003). Seismic displace- 
ments of geosynthetic-reinforced soil modular block walls. Geosynthetics Int. 10, No. 1, 2-23.

Jewell, R. A. (1996). Soil reinforcement with geotextiles, Construction Industry Research and Information Association (CIRIA), Special Publication 123. London, UK: Thomas Telford.

Jibson, R. W. (2007). Regression models for estimating coseismic landslide displacement. Engng Geol. 91, 209-218.

Leshchinsky, D. (2001). Design dilemma: use peak or residual strength of soil. Geotext. Geomembr. 19, No. 2, 111-125.

Leshchinsky, D. \& Vahedifard, F. (2012). Impact of toe resistance in reinforced masonry block walls: design dilemma. J. Geotech. Geoenviron. Engng 138, No. 2, 236-240.

Leshchinsky, D. \& Zhu, F. (2010). Resultant force of lateral earth pressure in unstable slopes. J. Geotech. Geoenviron. Engng 136, No. 12, 1655-1663.

Leshchinsky, D., Ling, H. I., Wang, J.-P., Rosen, A. \& Mohri, Y. (2009). Equivalent seismic coefficient in Geocell retention systems. Geotext. Geomembr. 27, No. 1, 9-18.

Leshchinsky, D., Zhu, F. \& Meehan, C. L. (2010). Required unfactored strength of geosynthetic in reinforced earth structures. J. Geotech. Geoenviron. Engng 136, No. 2, 281-289.

Leshchinsky, D., Ebrahimi, S., Vahedifard, F. \& Zhu, F. (2012). Extension of Mononobe-Okabe approach to unstable soils. Soils Found. 52, No. 2, 239-256

Ling, H. I., Leshchinsky, D. \& Perry, E. B. (1997). Seismic design and performance of geosynthetic-reinforced soil structures. Géotechnique 47, No. 5, 933-952, http://dx.doi.org/10.1680/ geot.1997.47.5.933.

Liu, H. \& Ling, H. I. (2012). Seismic responses of reinforced soil retaining walls and the strain softening of backfill soils. Int. $J$. Geomech. 12, No. 4, 351-356.

Michalowski, R. L. \& You, L. (2000). Displacements of reinforced slopes subjected to seismic loads. J. Geotech. Geoenviron. Engng 126, No. 8, 685-694.

Nakajima, S., Koseki, J., Watanabe, K. \& Tateyama, M. (2010). Simplified procedure to evaluate earthquake-induced residual displacement of geosynthetic reinforced soil retaining walls. Soils Found. 50, No. 5, 659-677.

NCMA (2009). Design manual for segmental retaining walls, 3rd edn. Herndon, VA, USA: National Concrete Masonry Association.

Newmark, N. M. (1965). Effect of earthquakes on dams and embankments. Géotechnique 15, No. 2, 139-159, http:// dx.doi.org/10.1680/geot.1965.15.2.139.

Paulsen, S. B. \& Kramer, S. L. (2004). A predictive model for seismic displacement of reinforced slopes. Geosynthetics Int. 11, No. 6, 407-428.

Vahedifard, F., Leshchinsky, D. \& Meehan, C. L. (2012). Relationship between the seismic coefficient and the unfactored geosynthetic force in reinforced earth structures. J. Geotech. Geoenviron. Eng. 138, No. 10, 1209-1221. 